\title{
Integrated Control of Five-Level Diode-Clamped Rectifiers
}

\author{
P Montero-Robina, F Umbría, F Salas, F Gordillo
}

Published paper: https://ieeexplore.ieee.org/stamp/stamp.jsp?arnumber $=8517128$ Montero-Robina, P., Umbría, F., Salas, F., \& Gordillo, F. (2018). Integrated Control of Five-Level Diode-Clamped Rectifiers. IEEE Transactions on Industrial Electronics, 66(9), 6628-6636.

Digital Object Identifier 10.1109/TIE.2018.2878121

(C) 2018 IEEE. Personal use of this material is permitted. Permission from IEEE must be obtained for all other uses, in any current or future media, including reprinting/republishing this material for advertising or promotional purposes, creating new collective works, for resale or redistribution to servers or lists, or reuse of any copyrighted component of this work in other works. 


\title{
Integrated Control of Five-Level Diode-Clamped Rectifiers
}

\author{
Pablo Montero-Robina, Francisco Umbría, Francisco Salas, Francisco Gordillo, \\ Senior Member
}

\begin{abstract}
This paper presents an approach for dealing with the control of five-level, diode-clamped rectifiers. The control of such converters is challenging since the voltage balancing among capacitors is not a trivial task. Some of the existing approaches that cope with this problem use specific modifications of one of the traditional modulation techniques such as using redundant vectors in SVM. The main feature of the proposed technique is that part of the modulation is considered in the system equations and, in this way, the voltage balance can be solved designing a specific controller for this problem. As a result, several levels are used within a switching period. Furthermore, it is shown that the proposed approach hardly affects the control of active and reactive powers and total dc-link voltage in such a way that the well-known direct power control (DPC) can be applied. As a consequence, the resultant modulation stage is simpler than other techniques based on, e.g., space vector modulation (SVM). The effectiveness and good performance of the system under the proposed control approach are validated by both simulation and experimental results.
\end{abstract}

\section{Index Terms}

Power conversion, multilevel converter, grid interface, diode-clamped converter (DCC), voltage balancing, Power Control

Manuscript received April 24, 2018; revised September 03, 2018; accepted October 09, 2018. This work has been funded under grants MINECO-FEDER DPI2013-41891-R and DPI2016-75294-C2-1-R.

P. Montero-Robina, F. Salas and F. Gordillo are with the Departamento de Ingeniería de Sistemas y Automática, Escuela Técnica Superior de Ingeniería, Universidad de Sevilla, 41092, Sevilla, Spain (e-mail: pmontero1@us.es; salas@us.es; gordillo@us.es).

F. Umbría is with ASM Assembly Systems GmbH \& Co. KG, Munich, Germany (email: umbriafrancisco@ hotmail.com). 


\section{INTRODUCTION}

Over the last decades, multilevel converters have emerged as a preferable solution for highpower applications and/or systems where low current distortion are required [1], [2]. Not only they offer the possibility of using lower-voltage switching devices in common applications, but also they improve the current distortion at the converter output. Nowadays, they have become a mature technology and they are used in several industrial applications such as energy conversion and generation, manufacturing or power transmission, among others [3], [4]. Despite there are some industrial well-established topologies, there is still plenty room for research as new topologies and algorithms are still being developed given the potentiality of this technology [4]-[6].

Among the different multilevel converter topologies, this paper focuses on the diode-clamped converter (DCC). Diode-clamped converter topology allows to set different voltage levels at the output of the converter thanks to the use of diodes that permit the current circulation from the grid to the selected level and vice versa. Despite they have been commercialized by a wide amount of companies, the exponential usage complexity when the number of levels is greater than three, limits its industrial implementation to three-level DCC [6].

The presence of several capacitors in the dc link leads to the control challenge for this kind of converters, that is, guaranteeing a proper voltage sharing among all of them. The aim of this paper is to present an implementable and easy-to-follow solution to this control objective in five-level DCCs with no additional cost. Several approaches have already been presented for the capacitor voltage balancing issue for five-level DCCs and can be primarily divided into several categories [7]: 1) using redundant switching vectors along with modulation strategies and control schemes or injecting zero-sequence voltages in the modulation signals of carrier-based modulators; 2) using additional circuitry; 3) applying algorithms for back-to-back converters; 4) defining a discrete-time dynamic model and applying a predictive control strategies; and 5) analyzing the capacitor voltage imbalance issue as a problem of regulating the multiple outputs of a nonlinear system subject to exogenous disturbances [8], [9]. The second approach requires additional hardware [10]-[12], which increases the converter cost and volume and, still it does not guarantee that control complexity is reduced, or even kept the same. The third approach is limited to specific applications where a back-to-back application is considered [13], [14] and, therefore, it is of no use when a standalone application is considered. 


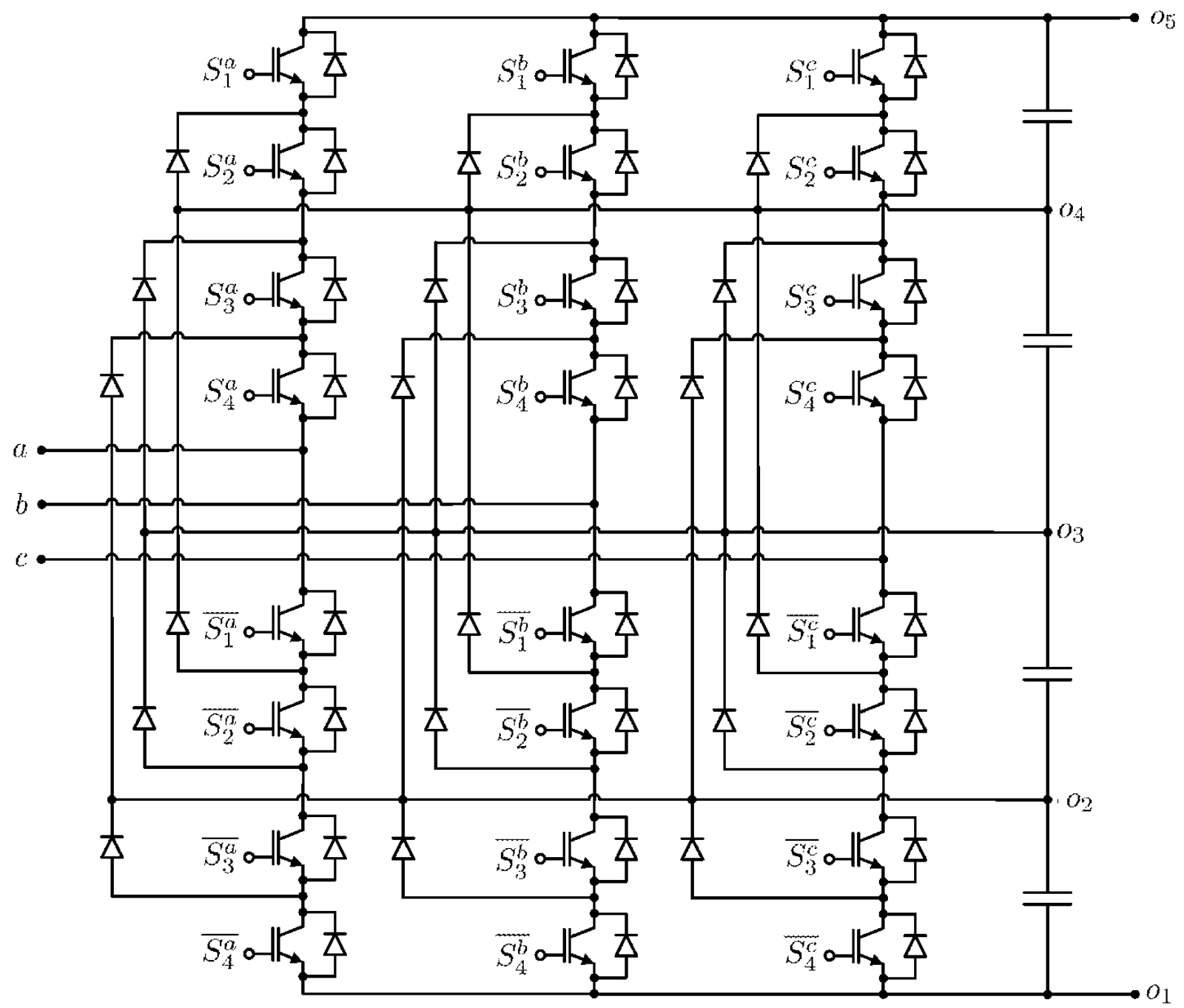

Fig. 1. Circuit of a three-phase five-level diode-clamped power converter.

A vast amount of practical solutions that exist are, in fact, related to the first category mentioned previously [15]-[21]. The considered solution consists of using the degree of freedom associated with the different switching combinations that achieve the same phase-to-phase converter voltage output, that is, circulating the phase current through different capacitors to regulate their own voltage without affecting the current performance. In [20], the SVM hexagon is separated in two regions according to the modulation index and a criteria for switching vector selection is provided. In [19] a criteria for selecting the redundant switching vector according to the most deviated capacitor is considered. However, this approach has some restrictions [22], [23] as redundant switching states may not appear when large modulation indexes are involved. The 
solution stated in [18] goes through considering all the degrees of freedom the converter has, that is, using several voltage levels within a switching period. Regarding the fourth approach, in [24] a low-computational-cost predictive control technique is analyzed and evaluated in simulations. Moreover, in [25] the problem is formulated as a linear, mixed-integer programming problem that it is solved off-line and implemented interpolating in a lookup table.

As stated previously, this paper is focused on the five-level DCC topology (Fig. 1) and its aim is to deal with the voltage capacitor imbalance issue in an analytical way during the controller design instead of attacking the problem during the modulation stage. Consequently, the amount of levels used within a switching period is increased, similarly to [18], in comparison with twonearest-level modulation approaches. On the whole, the advantages this approach offers are: 1) no external hardware required; 2) simple-to-use mathematical model; 3) different controllers can be implemented; and 4) computational burden lower than other approaches such as SVM or predictive techniques. Besides, the idea of using several levels within a switching period offers more degrees of freedom than the methods that use redundant switching vectors. Moreover, the technique could be extended to DCC converters with more than five levels by applying the corresponding set of control inputs. Obviously, the number of control inputs will increase as the level does although the simplicity of the implemented controller, as it will be shown, partially overcomes this issue. This work is an extension to [26] where the different control objectives are addressed separately using different set of control inputs. In [27] the same technique was successfully applied to a NPC rectifier. However, the previous work considered the five-level DCC converter as a grid interfacing inverter and only simulation results were presented. In this work, the necessary rearrange of the variables in order to work as a rectifier is considered, experimental results are included and the original current control has been replaced with a model-based direct power controller (DPC) [28] in order to show the flexibility of the proposed technique. Furthermore, a last modification in the algorithm is included which results in the reduction of the number of levels used per switching period.

The outline of the paper is as follows. Firstly, a brief explanation of the converter under study is given in Section II, along with the averaged dynamic model based on the duty ratios of each level at each phase. After this, Section III presents the decoupled model-based power and capacitor voltage balance controllers. Then, the algorithm modification is presented in Section IV. Afterwards, some simulation and experimental results with these controllers are shown and discussed in Section V. Finally, some conclusions are presented in Section VI. 


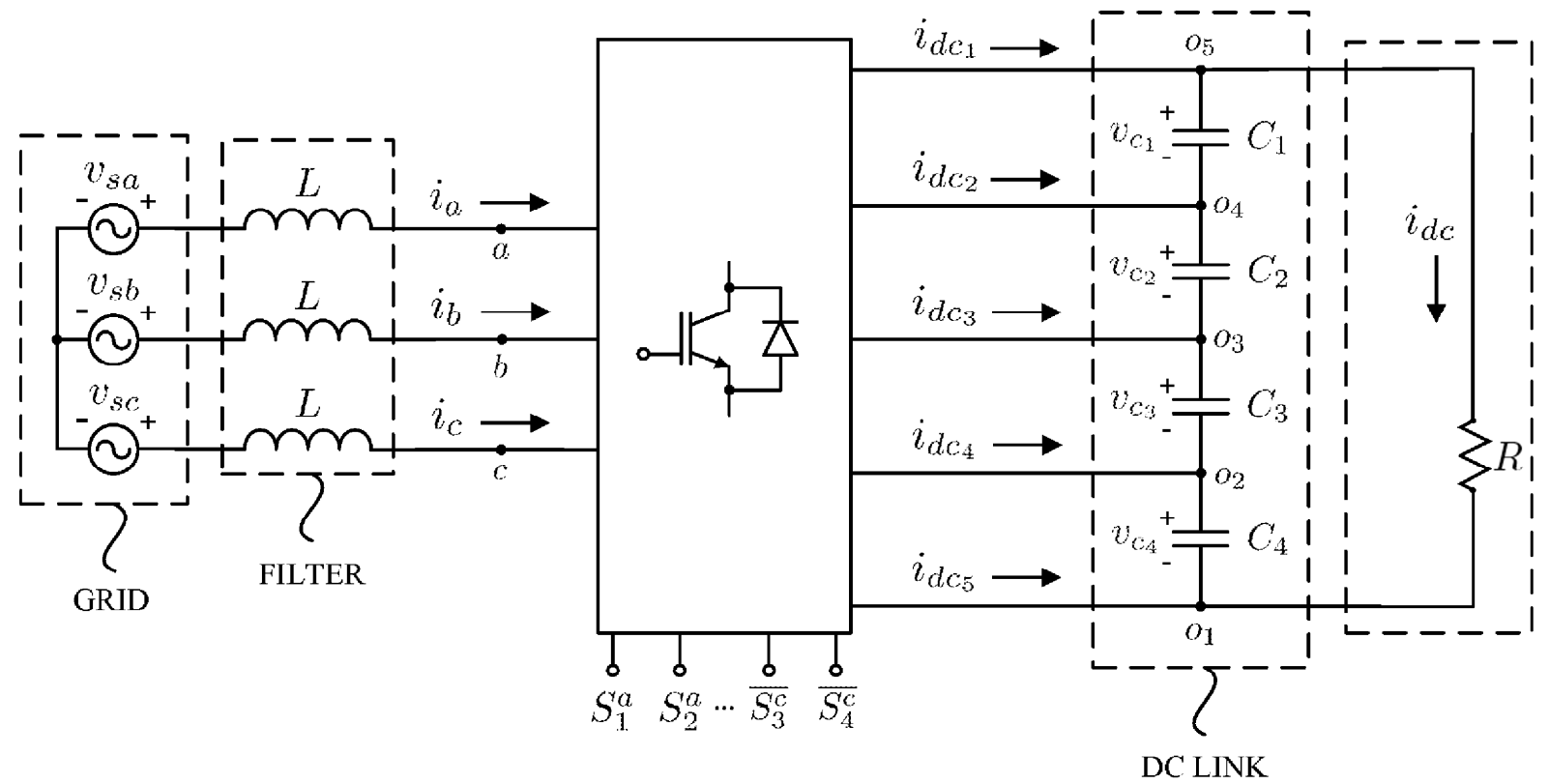

Fig. 2. Schematic diagram of the five-level diode-clamped converter operating as a rectifier connected to the utility grid.

\section{Model Equations}

\section{A. System Description}

The circuit configuration considered in this paper is depicted in Fig. 2 which illustrates a simple schematic diagram of the five-level DCC operating as a rectifier connected to the grid. The total dc-link voltage $V_{d c}$ has to be controlled and the power is dissipated in a dc-linkconnected resistor. The converter dc-link is composed of capacitors $C_{1}, C_{2}, C_{3}$ and $C_{4}$, all of identical capacitance $C$. Their respective voltages are represented by $v_{c_{1}}, v_{c_{2}}, v_{c_{3}}$ and $v_{c_{4}}$ attending to the criteria depicted in Fig. 2. Regarding the converter ac side, the phase voltages are denoted by $v_{s a}, v_{s b}$ and $v_{s c}$ and the phase currents are named $i_{a}, i_{b}$ and $i_{c}$ according to the sign criteria and phase depicted in Fig. 2. The filter inductors are considered to be equal and ideal, i.e., they all present the same inductance $L$.

The converter voltage output in phases $a, b$ and $c$, measured with respect to the dc-link midpoint $o_{3}$, are denoted by $v_{a}, v_{b}$ and $v_{c}$, respectively, and they represent the voltage set by the converter. These voltages depend on the converter switching states, which are determined by the switching functions $f_{i_{j}} \in\{0,1\}$-where $i=a, b, c ; j=1,2, \ldots, 5$ - defined in Table I.

Note that $S_{h}^{i}$ for $i=a, b, c$ and $h=1,2,3,4$ represent the semiconductor devices depicted in 
TABLE I

SWITCHING FUNCTION $f_{i_{j}}$ DEFINITION

\begin{tabular}{c||c|c|c|c||l}
$f_{i_{j}}$ & $S_{1}^{i}$ & $S_{2}^{i}$ & $S_{3}^{i}$ & $S_{4}^{i}$ & $v_{i}$ \\
\hline \hline$f_{i_{1}}=1$ & 0 & 0 & 0 & 0 & $-v_{c_{3}}-v_{c_{4}}$ \\
\hline$f_{i_{2}}=1$ & 0 & 0 & 0 & 1 & $-v_{c_{3}}$ \\
\hline$f_{i_{3}}=1$ & 0 & 0 & 1 & 1 & 0 \\
\hline$f_{i_{4}}=1$ & 0 & 1 & 1 & 1 & $v_{c_{2}}$ \\
\hline$f_{i_{5}}=1$ & 1 & 1 & 1 & 1 & $v_{c_{1}}+v_{c_{2}}$
\end{tabular}

Fig. 1. Thereby, each switching function $f_{i_{j}}$ represents whether the terminal $i$ of the converter is connected to the dc-link point $o_{j}\left(f_{i_{j}}=1\right)$ or not $\left(f_{i_{j}}=0\right)$. In this manner, it is obvious that the expression $f_{i_{1}}+f_{i_{2}}+f_{i_{3}}+f_{i_{4}}+f_{i_{5}} \leq 1$ for $i=a, b, c$, has to be satisfied. In other words, each ac-side points $a, b$ and $c$ can be connected to only one of the points $o_{1}, o_{2}, o_{3}, o_{4}$ or $o_{5}$ of the dc-link. It is assumed that there is always a switching state activated, i.e. the case of all switches turned-off is not considered. Then $f_{i_{1}}+f_{i_{2}}+f_{i_{3}}+f_{i_{4}}+f_{i_{5}}=1$.

\section{B. Averaged Model}

As stated in [26], an averaged model in $\alpha \beta \gamma$ frame within a switching period can be considered when facing power control. Therefore, the switching functions $f_{i_{j}}$ can be averaged and then transformed into the $\alpha \beta \gamma$ frame resulting in the variables $d_{k_{j}}$ for $k=\alpha, \beta, \gamma$. These variables represent the fraction of a switching period when the transformed phase $k$ is connected to the point $o_{j}$. It is also possible to transform them reversely from $\alpha \beta \gamma$ to $a b c$, in which case they will be referred as duty ratios of phase $i$ and level $j$. From [26], assuming that the capacitor voltages are similar $\left(v_{c_{1}} \simeq v_{c_{2}} \simeq v_{c_{3}} \simeq v_{c_{4}}\right)$, taking into account the definition of the switching functions, the Kirchhoff's laws and considering the duty ratios explained previously, the averaged model 
is obtained as

$$
\begin{aligned}
L \frac{d i_{\alpha}}{d t} & =v_{s \alpha}-\left(2 d_{\alpha_{5}}+d_{\alpha_{4}}-d_{\alpha_{2}}-2 d_{\alpha_{1}}\right) \frac{V_{d c}}{4} \\
L \frac{d i_{\beta}}{d t} & =v_{s \beta}-\left(2 d_{\beta_{5}}+d_{\beta_{4}}-d_{\beta_{2}}-2 d_{\beta_{1}}\right) \frac{V_{d c}}{4} \\
C \frac{d v_{c 1}}{d t} & =d_{\alpha_{5}} i_{\alpha}+d_{\beta_{5}} i_{\beta}-i_{d c} \\
C \frac{d v_{c 2}}{d t} & =\left(d_{\alpha_{5}}+d_{\alpha_{4}}\right) i_{\alpha}+\left(d_{\beta_{5}}+d_{\beta_{4}}\right) i_{\beta}-i_{d c} \\
C \frac{d v_{c 3}}{d t} & =-\left(d_{\alpha_{1}}+d_{\alpha_{2}}\right) i_{\alpha}-\left(d_{\beta_{1}}+d_{\beta_{2}}\right) i_{\beta}-i_{d c} \\
C \frac{d v_{c 4}}{d t} & =-d_{\alpha_{1}} i_{\alpha}-d_{\beta_{1}} i_{\beta}-i_{d c},
\end{aligned}
$$

where $v_{s \alpha}, v_{s \beta}$ and $i_{\alpha}, i_{\beta}$ are the grid voltages $v_{s a}, v_{s b}, v_{s c}$ and the grid currents $i_{a}, i_{b}, i_{c}$ transformed to $\alpha \beta \gamma$. Note that the power-invariant version of the Clarke transformation is being used. It can be seen that $d_{\gamma_{1}}, d_{\gamma_{2}}, d_{\gamma_{3}}, d_{\gamma_{4}}$ and $d_{\gamma_{5}}$ do not appear in the dynamical model and, as a consequence, they do not have a direct effect on it but they still remain as control inputs.

In order to express the capacitor voltage unbalances, three error signals are defined by

$$
\begin{aligned}
& v_{d_{1}}=v_{c_{4}}-v_{c_{1}} \\
& v_{d_{2}}=v_{c_{3}}-v_{c_{2}} \\
& v_{d_{3}}=v_{c_{2}}-v_{c_{1}} .
\end{aligned}
$$

Substituting (3)-(6) into the definition of $v_{d_{1}}, v_{d_{2}}$ and $v_{d_{3}}$, the error signal dynamics become

$$
\begin{aligned}
C \frac{d v_{d_{1}}}{d t}= & -\left(d_{\alpha_{5}}+d_{\alpha_{1}}\right) i_{\alpha}-\left(d_{\beta_{5}}+d_{\beta_{1}}\right) i_{\beta} \\
C \frac{d v_{d_{2}}}{d t}= & -\left(d_{\alpha_{1}}+d_{\alpha_{2}}+d_{\alpha_{4}}+d_{\alpha_{5}}\right) i_{\alpha} \\
& -\left(d_{\beta_{1}}+d_{\beta_{2}}+d_{\beta_{4}}+d_{\beta_{5}}\right) i_{\beta} \\
C \frac{d v_{d_{3}}}{d t}= & d_{\alpha_{4}} i_{\alpha}+d_{\beta_{4}} i_{\beta} .
\end{aligned}
$$

On the other hand, considering the provided definition of duty ratios, the following equation has to be fulfilled

$$
d_{i_{1}}+d_{i_{2}}+d_{i_{3}}+d_{i_{4}}+d_{i_{5}}=1, \text { for } i=\{a, b, c\} \text {. }
$$

By considering this constraint, the duty ratios corresponding to level $3-d_{i_{3}}-$ are defined as a function of the remaining ones. 


\section{CONTRoller Design}

This section is devoted to present several control stages that, in the whole, achieve the proper performance of the converter, namely: power control, total dc-link regulation and capacitor voltage balancing. First of all, a change of variables inspired by (1)-(2) and (10)-(12) is applied in order to considerably simplify the averaged model

$$
\begin{gathered}
T_{\alpha \beta \rightarrow u}=\left(\begin{array}{rrrr}
2 & 1 & -1 & -2 \\
1 & 0 & 0 & 1 \\
1 & 1 & 1 & 1 \\
0 & -1 & 0 & 0
\end{array}\right) \\
\left(\begin{array}{l}
u_{1} \\
u_{3} \\
u_{5} \\
u_{7}
\end{array}\right)=T_{\alpha \beta \rightarrow u}\left(\begin{array}{l}
d_{\alpha_{5}} \\
d_{\alpha_{4}} \\
d_{\alpha_{2}} \\
d_{\alpha_{1}}
\end{array}\right) ;\left(\begin{array}{l}
u_{2} \\
u_{4} \\
u_{6} \\
u_{8}
\end{array}\right)=T_{\alpha \beta \rightarrow u}\left(\begin{array}{l}
d_{\beta_{5}} \\
d_{\beta_{4}} \\
d_{\beta_{2}} \\
d_{\beta_{1}}
\end{array}\right) .
\end{gathered}
$$

These new control variables, $u_{l}$ for $l=1,2, \ldots, 8$, are expressed in terms of the duties shown in (1)-(12). By doing so, the behavior of the system can be easily controlled by means of a set of equations that define the value of variables $u_{l}$ for $l=1,2, \ldots, 8$. In summary, the value of these variables will be defined by the appropriate control laws and the variable change (14) can be reverted to obtain the value of the duties.

\section{A. Power Controllers}

According to [29], the instantaneous powers of the three-phase circuit can be obtained in the $\alpha \beta$ frame by applying

$$
\begin{aligned}
& p=v_{s \alpha} i_{\alpha}+v_{s \beta} i_{\beta} \\
& q=-v_{s \alpha} i_{\beta}+v_{s \beta} i_{\alpha},
\end{aligned}
$$

where variables $p$ and $q$ represent the instantaneous active and reactive powers, respectively. In this case, the controller should be designed in such a way that the instantaneous powers are regulated to achieve the desired amount of active power $p_{r e f}$, set by the total dc-link voltage control, and the specified amount of reactive power $q_{\text {ref }}$, commonly equal to 0 to achieve unity power factor. 
Therefore, considering the change of variables (14), the current dynamics (1)-(2) are expressed now by

$$
\begin{aligned}
& L \frac{d i_{\alpha}}{d t}=v_{s \alpha}-\frac{1}{4} u_{1} V_{d c} \\
& L \frac{d i_{\beta}}{d t}=v_{s \beta}-\frac{1}{4} u_{2} V_{d c} .
\end{aligned}
$$

Applying these equations into the definition of instantaneous powers (15)-(16), the power dynamics are obtained as

$$
\begin{aligned}
& L \frac{d p}{d t}=v_{s \alpha}^{2}+v_{s \beta}^{2}+2 \pi f L q-\left(u_{1} v_{s \alpha}+u_{2} v_{s \beta}\right) \frac{V_{d c}}{4} \\
& L \frac{d q}{d t}=-2 \pi f L p+\left(u_{1} v_{s \beta}-u_{2} v_{s \alpha}\right) \frac{V_{d c}}{4} .
\end{aligned}
$$

These derived power dynamics are similar to those of the two-level converter and, therefore, any of the numerous control strategies widely studied over the last years [30]- [31] can be implemented. In this paper, the solution considered is adopted from [28], where a model-based DPC control is presented, yielding

$$
\begin{aligned}
u_{1} & =u_{1}^{z}+k_{p} v_{s \alpha}\left(p-p_{r e f}\right)+k_{p i} v_{s \alpha} \int_{0}^{t}\left(p-p_{r e f}\right) d \tau \\
& -k_{q} v_{s \beta}\left(q-q_{r e f}\right)-k_{q i} v_{s \beta} \int_{0}^{t}\left(q-q_{r e f}\right) d \tau \\
u_{2} & =u_{2}^{z}+k_{p} v_{s \beta}\left(p-p_{r e f}\right)+k_{p i} v_{s \beta} \int_{0}^{t}\left(p-p_{r e f}\right) d \tau \\
& +k_{q} v_{s \alpha}\left(q-q_{r e f}\right)+k_{q i} v_{s \alpha} \int_{0}^{t}\left(q-q_{r e f}\right) d \tau,
\end{aligned}
$$

where

$$
\begin{aligned}
& u_{1}^{z}=\frac{4}{v_{d c}}\left(\left(1+\frac{2 \pi f L q}{v_{s \alpha}^{2}+v_{s \beta}^{2}}\right) v_{s \alpha}+\frac{2 \pi f L p}{v_{s \alpha}^{2}+v_{s \beta}^{2}} v_{s \beta}\right) \\
& u_{2}^{z}=\frac{4}{v_{d c}}\left(\left(1+\frac{2 \pi f L q}{v_{s \alpha}^{2}+v_{s \beta}^{2}}\right) v_{s \beta}-\frac{2 \pi f L p}{v_{s \alpha}^{2}+v_{s \beta}^{2}} v_{s \alpha}\right),
\end{aligned}
$$

and the design parameters $k_{p}, k_{q}, k_{p i}$ and $k_{q i}$ are the proportional and integral controller gains. These equations can be represented by the block diagram depicted in Fig. 3 .

\section{B. Total DC-Link Voltage Controller}

In order to keep the dc-link voltage at the desired value, a PI controller is used [28], [32]

$$
p_{\text {ref }}=k_{p}^{v_{d c}}\left(v_{d c_{\text {ref }}}^{2}-v_{d c}^{2}\right)+k_{i}^{v_{d c}} \int_{0}^{t}\left(v_{d c_{r e f}}^{2}-v_{d c}^{2}\right) d \tau,
$$




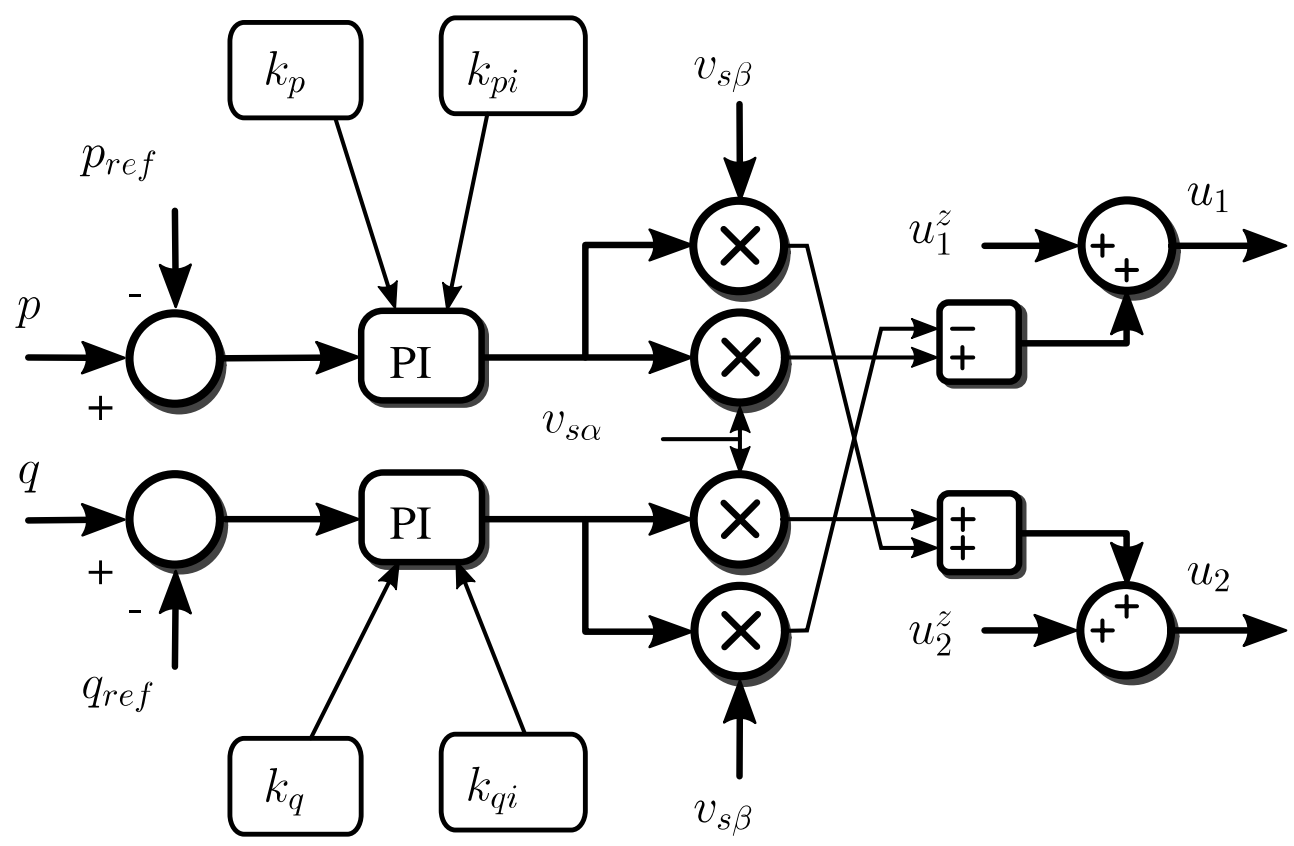

Fig. 3. Schematic diagram of the power controller

where constants $k_{p}^{v_{d c}}$ and $k_{i}^{v_{d c}}$ are the controller tuning parameters. The value $v_{d c_{r e f}}$ is set by the user, usually, as a constant. The output of this controller $p_{r e f}$ is the input for the active power controller.

\section{Capacitor Voltage Balance Controller}

Regarding the balancing of the dc-link capacitor voltages, a model-based controller is proposed in [26]. It is based on the particular equations of the dynamics of the error signals, which can be expressed by substituting (14) into (10)-(12) yielding

$$
\begin{aligned}
& C \frac{d v_{d_{1}}}{d t}=-u_{3} i_{\alpha}-u_{4} i_{\beta} \\
& C \frac{d v_{d_{2}}}{d t}=-u_{5} i_{\alpha}-u_{6} i_{\beta} \\
& C \frac{d v_{d_{3}}}{d t}=-u_{7} i_{\alpha}-u_{8} i_{\beta} .
\end{aligned}
$$

Notice the advantage of the proposed change of variables (14). A complete decoupling of the control variables can be achieved for the different control objectives. On one hand, $u_{1}$ and $u_{2}$ are used to regulate the power variables $p$ and $q$ as mentioned previously, on the other hand, control variables $u_{3}, u_{4}, u_{5}, u_{6}, u_{7}$ and $u_{8}$ remain as degrees of freedom that can be used to balance 
the voltage capacitors. To regulate the error signals $v_{d_{1}}, v_{d_{2}}$ and $v_{d_{3}}$ these control variables are defined as

$$
\left(\begin{array}{l}
u_{3} \\
u_{4} \\
u_{5} \\
u_{6} \\
u_{7} \\
u_{8}
\end{array}\right)=\left(\begin{array}{ccc}
i_{\alpha} & 0 & 0 \\
i_{\beta} & 0 & 0 \\
0 & i_{\alpha} & 0 \\
0 & i_{\beta} & 0 \\
0 & 0 & i_{\alpha} \\
0 & 0 & i_{\beta}
\end{array}\right)\left(\begin{array}{l}
k_{1} v_{d 1} \\
k_{2} v_{d 2} \\
k_{3} v_{d 3}
\end{array}\right)
$$

where $k_{1}, k_{2}$ and $k_{3}$ are positive constant design parameters.

Introducing these control laws into the error signal dynamics, the closed-loop dynamics are described by

$$
\begin{aligned}
& C \frac{d v_{d_{1}}}{d t}=-k_{1} i_{\alpha}^{2} v_{d_{1}}-k_{1} i_{\beta}^{2} v_{d_{1}} \\
& C \frac{d v_{d_{2}}}{d t}=-k_{2} i_{\alpha}^{2} v_{d_{2}}-k_{2} i_{\beta}^{2} v_{d_{2}} \\
& C \frac{d v_{d_{3}}}{d t}=-k_{3} i_{\alpha}^{2} v_{d_{3}}-k_{3} i_{\beta}^{2} v_{d_{3}} .
\end{aligned}
$$

Knowing that $i_{\alpha}^{2}+i_{\beta}^{2}>0$, it can be easily seen that variables $v_{d_{i}}$ tend to zero for the controlled system (30)-(32), assuring its stability [26].

\section{Duty Ratios Computation}

By using (29) and the DPC controller (21)-(22), $u_{1}, u_{2}, \ldots, u_{8}$ are determined. Now it is necessary to revert the change of variables (14) to obtain the duty ratios values, which result in

$$
\begin{gathered}
T_{\alpha \beta \rightarrow u}^{-1}=T_{u \rightarrow \alpha \beta}=\left(\begin{array}{rrrr}
\frac{1}{4} & \frac{1}{4} & \frac{1}{4} & \frac{2}{4} \\
0 & 0 & 0 & -1 \\
0 & -1 & 1 & 1 \\
-\frac{1}{4} & \frac{3}{4} & -\frac{1}{4} & -\frac{2}{4}
\end{array}\right) \\
\left(\begin{array}{l}
d_{\alpha_{5}} \\
d_{\alpha_{4}} \\
d_{\alpha_{2}} \\
d_{\alpha_{1}}
\end{array}\right)=T_{u \rightarrow \alpha \beta}\left(\begin{array}{l}
u_{1} \\
u_{3} \\
u_{5} \\
u_{7}
\end{array}\right) ;\left(\begin{array}{l}
d_{\beta_{5}} \\
d_{\beta_{4}} \\
d_{\beta_{2}} \\
d_{\beta_{1}}
\end{array}\right)=T_{u \rightarrow \alpha \beta}\left(\begin{array}{l}
u_{2} \\
u_{4} \\
u_{6} \\
u_{8}
\end{array}\right) .
\end{gathered}
$$

As a result, eight duty ratios in $\alpha \beta$ frame are obtained. Thus, transforming these variables into $a b c$ frame is elemental by using the inverse Clarke transformation. Notice that the values of $d_{\gamma_{1}}, d_{\gamma_{2}}, d_{\gamma_{1}}$ and $d_{\gamma_{5}}$ have not been taken into account until now. In [26] some guidelines are given in order to avoid saturations by making $d_{\gamma_{j}}$ equal to a constant value denoted $k_{\gamma_{j}}$ for 


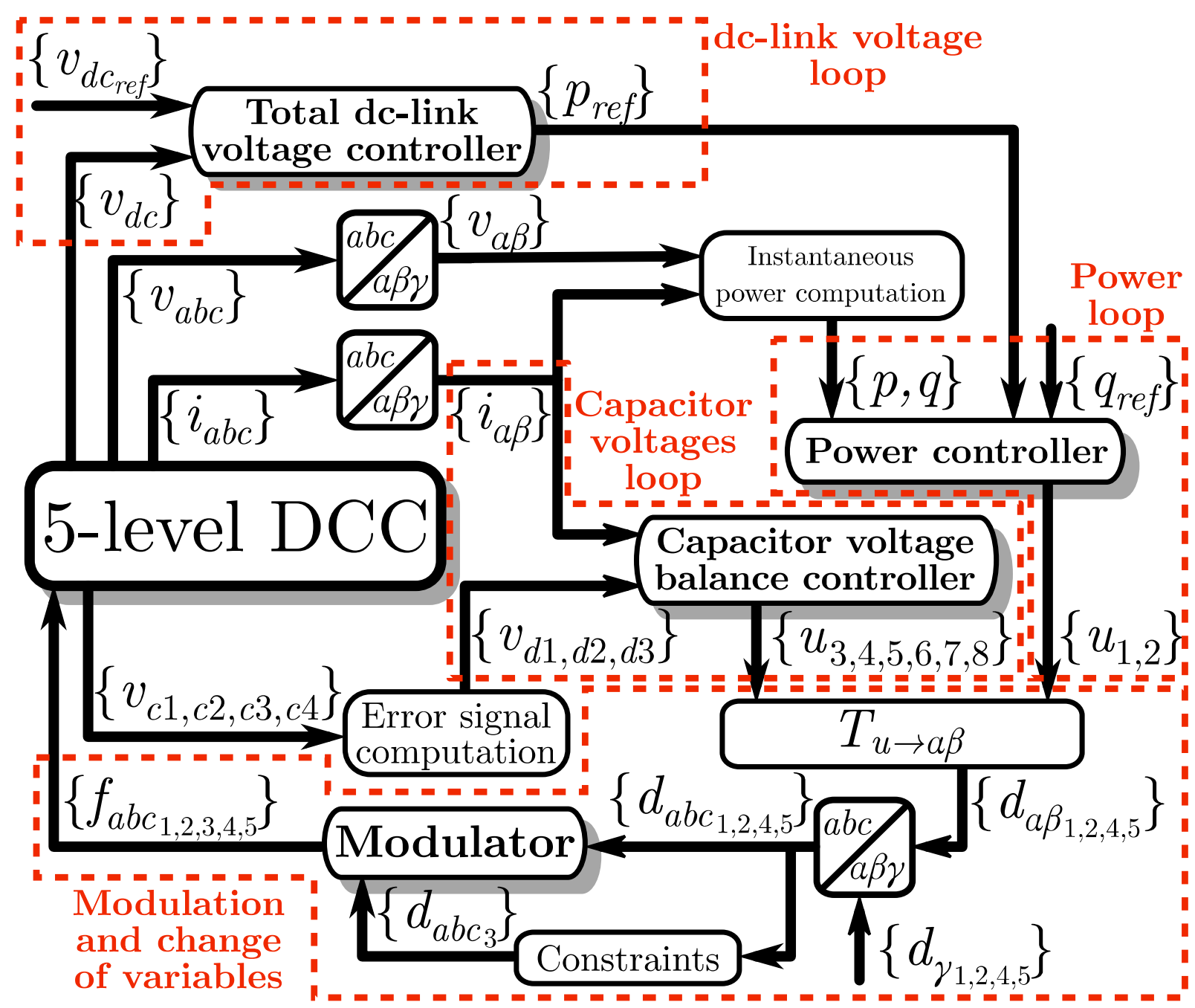

Fig. 4. Schematic block diagram of the whole control system.

$j=\{1,2,4,5\}$. In the next section, reduction in the number of commutations is also considered by selecting a proper value of $d_{\gamma_{j}}$.

Finally, the use of (13) will yield the three remaining duty ratios $d_{a_{3}}, d_{b_{3}}$ and $d_{c_{3}}$. After this, the modulation stage takes place to set the switching functions $f_{i_{j}}$, for $i=a, b, c$ and $j=1, \ldots, 5$ at every sampling time. A schematic block diagram that represents the implemented controls is depicted in Fig. 4.

\section{Algorithm ImProvement}

The values of $d_{\gamma_{1}}, d_{\gamma_{2}}, d_{\gamma_{4}}$ and $d_{\gamma_{5}}$ have a direct impact on the duties value: a higher value of $d_{\gamma_{j}}$ would lead to greater values of $d_{a_{j}}, d_{b_{j}}$ and $d_{c_{j}}$. This fact highlights the importance of 
selecting a proper value of $d_{\gamma_{j}}$ in such a way that duty saturation is avoided, i.e., $d_{i_{j}}$ remains in the interval $[0,1]$. As stated before, [26] gives some guidelines for proper delimiting of $d_{\gamma_{j}}$ values to avoid saturation in steady state performance. Nevertheless, some degrees of freedom remain that could be used to achieve another control objectives. In this section, an algorithm is proposed for the choice of $d_{\gamma_{j}}$ in order to also reduce the number of commutations and, thus, the switching losses.

For this, at every sampling instant, the inverse power-invariant Clarke transformation has to be analyzed at every level $j$, in search for a value of $d_{\gamma_{j}}$ that makes one of the duties $d_{i_{j}}(i=a, b, c)$ equal to zero and, at the same time, fulfills the saturation constrains. By doing so, the phase whose duty has been made zero is not set at the corresponding level during the sampling interval, avoiding extra-commutations.

Using the inverse Clarke transformation, the three values of $d_{\gamma_{j}}$ for which one $d_{i_{j}}=0$ can be computed as

$$
\begin{aligned}
& d_{a_{j}}=0 \rightarrow d_{\gamma_{j}}^{a}=-\sqrt{2} d_{\alpha_{j}} \\
& d_{b_{j}}=0 \rightarrow d_{\gamma_{j}}^{b}=\frac{d_{\alpha_{j}}}{\sqrt{2}}-d_{\beta_{j}} \sqrt{\frac{3}{2}} \\
& d_{c_{j}}=0 \rightarrow d_{\gamma_{j}}^{c}=\frac{d_{\alpha_{j}}}{\sqrt{2}}+d_{\beta_{j}} \sqrt{\frac{3}{2}} .
\end{aligned}
$$

Given that in the Clarke transformation the relationship between the $d_{i_{j}}$ and $d_{\gamma_{j}}$ is monotonically increasing, the greatest value among (34)-(36) for each $j=1,2,4,5$ has to be chosen in order to avoid the values less than zero. The upper constraint $d_{i_{j}} \leq 1$ has to be checked and, in the case is not fulfilled, the commutation reduction is not possible and duty saturation is unavoidable and it will be for any other procedure for selection of $d_{\gamma_{j}}$. Considering this, Fig. 5 shows the planes that are defined by (34)-(36) for a level $j$. The selection can be interpreted as the largest vertical value for the three points associated with the given values $d_{\alpha_{j}}, d_{\beta_{j}}$. As a result, one value of $d_{i_{j}}$ for $i=a, b, c$ will be zero. This choice has to be performed four times for $j=1,2,4,5$ in such a way that four duty ratios are equal to zero.

However, the cases $j=2$ and $j=4$ deserve special attention. Making $d_{j_{2}}$ or $d_{j_{4}}$ equal to zero could force the converter to switch between levels that are not consecutive, e.g. the case $d_{a_{5}} \neq 0, d_{a_{4}}=0, d_{a_{3}} \neq 0$. This behavior is not desirable since it would compromise the voltage limits of the switching devices. To avoid this, the selection of one $d_{\gamma_{j}}^{i}$ for $j=2,4$ is only considered if the duty cycle for phase $i$ and the extreme level next to $j$ has been equal to zero 


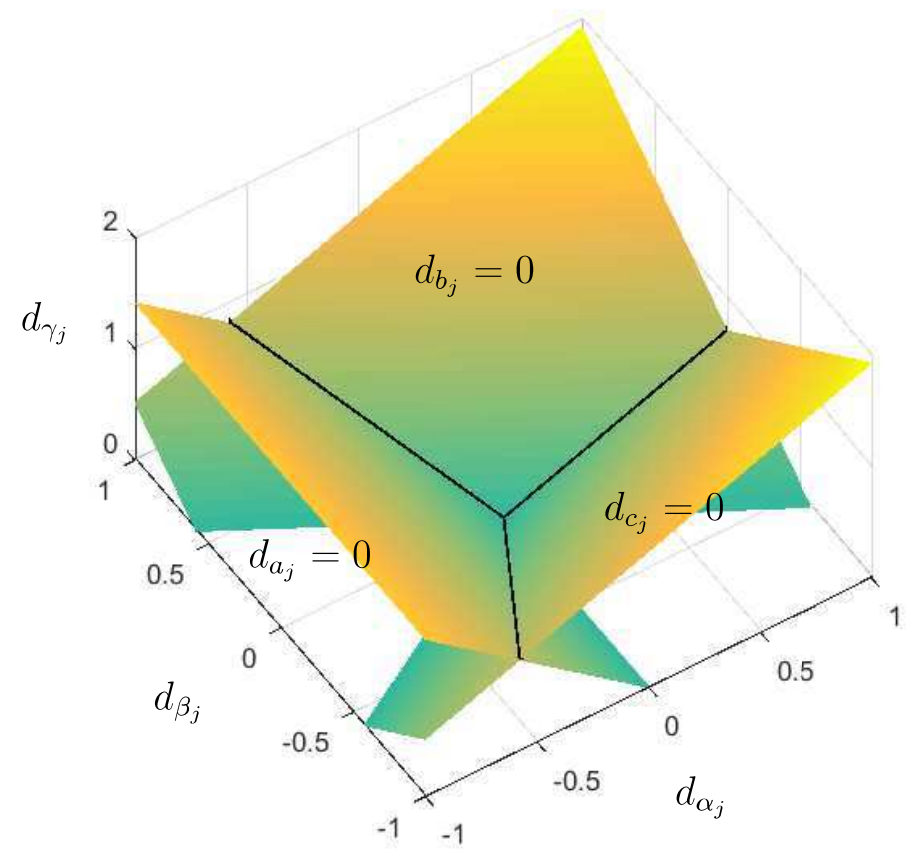

Fig. 5. The three planes that makes one duty $d_{i_{j}}=0$ for $i=a, b, c$ in the $\alpha \beta \gamma$ frame. These planes are defined by equations (34), (35) and (36)

as a result of the previous computations. This algorithm is depicted in Fig. 6 for levels $j=4,5$ and it can be easily extrapolated to levels $j=1,2$.

As a result, at each sampling time, there are only two phases that commute at level 1 and 5 , and it is also possible that the same phase does not commute at the consecutive level 2 or 4 , depending on the value of $d_{\alpha_{2}}, d_{\beta_{2}}$ or $d_{\alpha_{4}}, d_{\beta_{4}}$, respectively.

\section{Simulation AND Experimental Results}

In this section some experimental results are presented to verify the validity of the algorithm. The system used for this purpose is shown in Fig. 7, whose output power is rated up to 15 KVA. The values of converter and controller parameters are summarized in Table II. From the control signals, $d_{i_{j}}$ for $i=a, b, c$ and $j=1,2, \ldots, 5$, the switching sequence is generated by emulating the modulation of a typical CB-PWM where a triangular carrier wave is used. In order to show the system behaviour under different conditions, the resistive load $(R)$ and the voltage reference in the dc-link are modified during the simulation. The load is abruptly modified from $120 \Omega$ to 


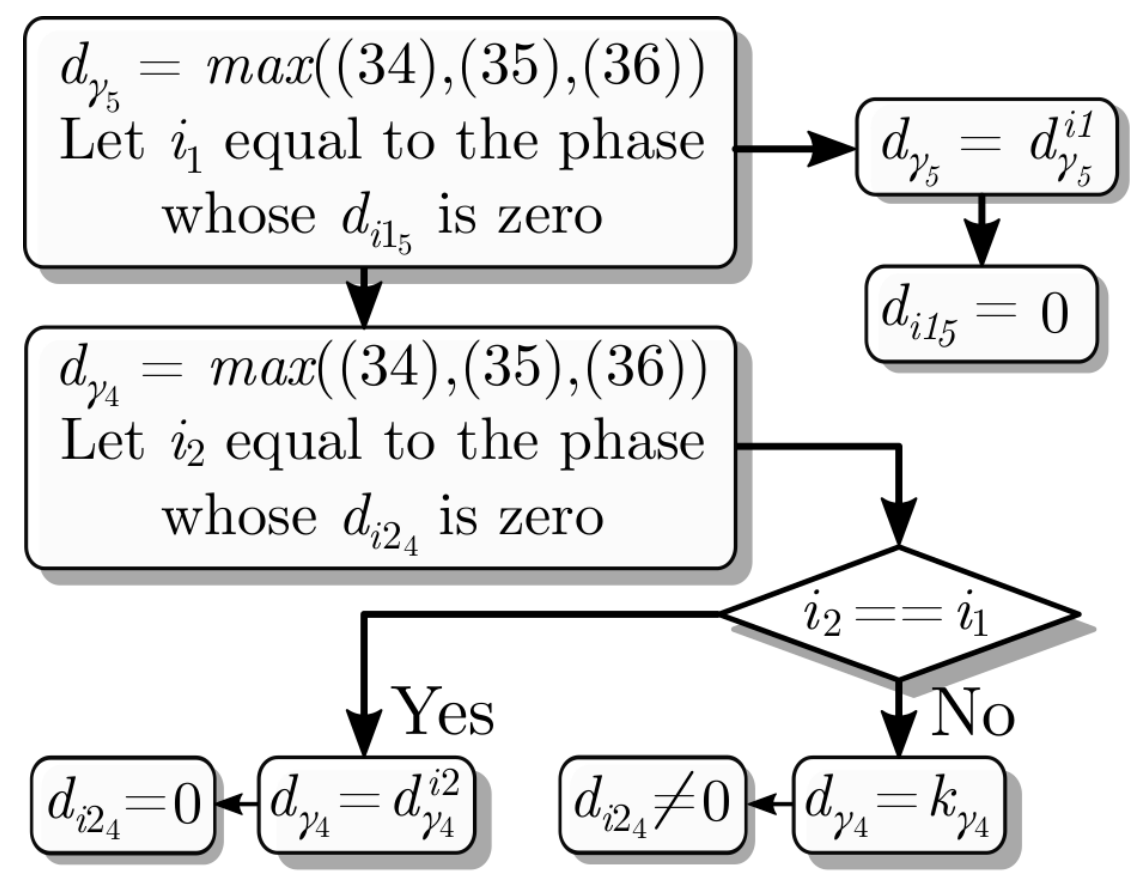

Fig. 6. Schematic diagram of the algorithm modification implementation for levels $j=4$ and $j=5$

TABLE II

SIMULATION AND EXPERIMENTAL PARAMETERS

\begin{tabular}{ll||ll} 
Parameter & Value & Parameter & Value \\
\hline \hline$f_{s w}$ & $10 \mathrm{kHz}$ & $k_{p}$ & $3 \cdot 10^{-7}$ \\
\hline$f_{\text {grid }}$ & $50 \mathrm{~Hz}$ & $k_{i}$ & $5 \cdot 10^{-5}$ \\
\hline$v_{s a}, v_{s b}, v_{s c}$ & $230 \mathrm{~V}_{\mathrm{RMS}}$ & $k_{p}^{v_{d c}}$ & 0.05 \\
\hline$L$ & $2 \mathrm{mH}$ & $k_{i}^{v_{d c}}$ & 1 \\
\hline$C$ & $3300 \mu \mathrm{F}$ & $k_{1}, k_{2}, k_{3}$ & $5 \cdot 10^{-5}$ \\
\hline$v_{d c_{r e f}}$ & $700 \rightarrow 800 \mathrm{~V}$ & $k_{\gamma_{1}}, k_{\gamma_{5}}$ & 0.7 \\
\hline$R$ & $120 \rightarrow 60 \Omega$ & $k_{\gamma_{2}}, k_{\gamma_{4}}$ & 0.1 \\
\hline$q_{r e f}$ & $0 \mathrm{VAr}$ & &
\end{tabular}

$60 \Omega$ at time $t=0.7 \mathrm{~s}$ whereas the voltage reference is modified as a ramp from $700 V_{d c}$ to $800 V_{d c}$ starting at $t=2.6 \mathrm{~s}$ with a slope of $150 \mathrm{~V} / \mathrm{s}$. Afterwards, the load is brought back to $120 \Omega$ at $t=4.7 \mathrm{~s}$.

The control variables $u_{l}$ defined by the DPC Controller and (29) are computed at the beginning 
of each sampling period, and then the transformation procedure illustrated in Fig. 4 is applied. For the original algorithm, variables $d_{\gamma_{1}}, d_{\gamma_{2}}, d_{\gamma_{4}}$ and $d_{\gamma_{5}}$ are assumed to be constant and equal to parameters $k_{\gamma_{1}}, \ldots, k_{\gamma_{5}}$ shown in table II. Regarding the algorithm modification, these variable are computed according to Fig. 6.

The software is programmed in a Speedgoat real-time target machine using Matlab Simulink. Figure 7 shows the real-time software machine along with several stages of the converter. The semiconductor devices are mounted in different trays for each phase together with the dc-link capacitors and the IGBT gate drivers (at each side of the tray - not shown in Fig. 7). The relays shown in this figure are used for the capacitor precharge and grid-connection maneuvers. The current distortion is measured with a power quality analyzer Fluke-435 and the grid currents are sensed with current probes.

In the following, the results of the experiments are presented. In some of the figures, simulation results are also included to corroborate the validity of the model. Figure 8 shows the behavior of total dc-link voltage with the changes described previously. Figure 9 depicts the behaviour of the phase currents in steady state with $R=60 \Omega$ and $v_{d c}=800 \mathrm{~V}$. Figure 10 shows the instantaneous power of the system for both the original algorithm and the modified one along with the simulation results for the same procedure. Experimental results present a higher ripple than simulated ones due to the presence of non-idealities in real equipments, such as calibration of sensors, presence of noise and sample delays among others. Still, both cases perform an acceptable reference-tracking and the experimental behaviour is similar to the simulated one.

On the other hand, Fig. 11 shows the evolution of the error signals in simulations and experiments when starting from a unbalanced situation for both the original algorithm and the modified one. Several tests have been performed depicting them when parameters $k_{1}, k_{2}$ and $k_{3}$ are set with different values. Generally, the higher the parameter value the less time it takes to correct the unbalance. However, a high value of these parameters could lead to instability in the transitory events due to saturation of the duty ratios. Therefore, the selection of these value has to be regarded as a trade-off between unbalance correction speed and robustness. These tests are carried out with $R=120 \Omega$ and $v_{d c}=700 \mathrm{~V}$. In some cases, specially for small values of $k_{1}, k_{2}$ and $k_{3}$ there are some noticeable differences between simulations and experiments that could be explained by the presence of dead-times and turn-on/turn-off semiconductor delays. A low value of the balancing control parameters $-k_{1}, k_{2}, k_{3}$ - could result in a low value of the control signals that would yield a low value of a duty ratio. If this duty ratio value is small 


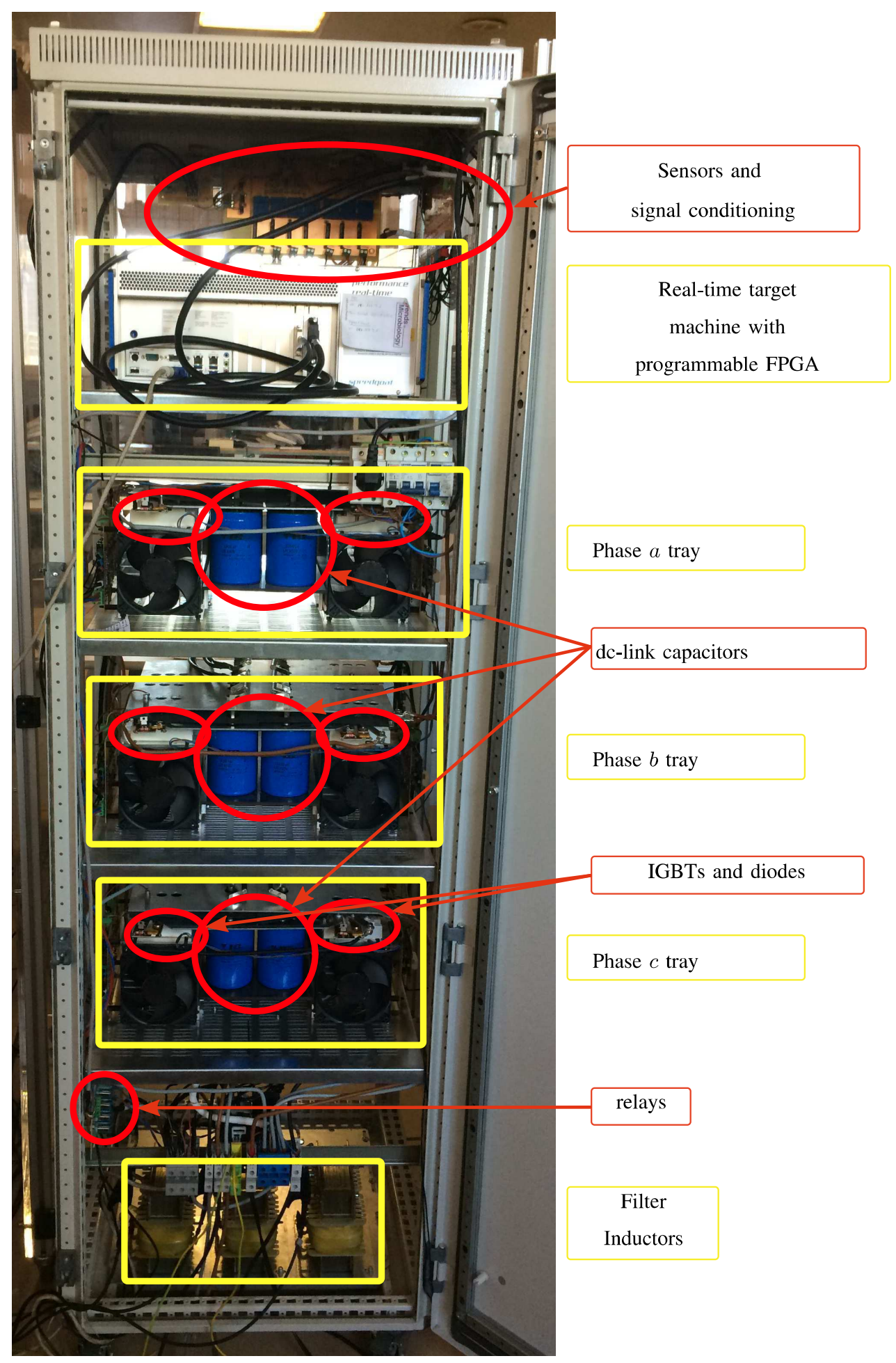

Fig. 7. Five-level DCC used to obtain the experimental results 


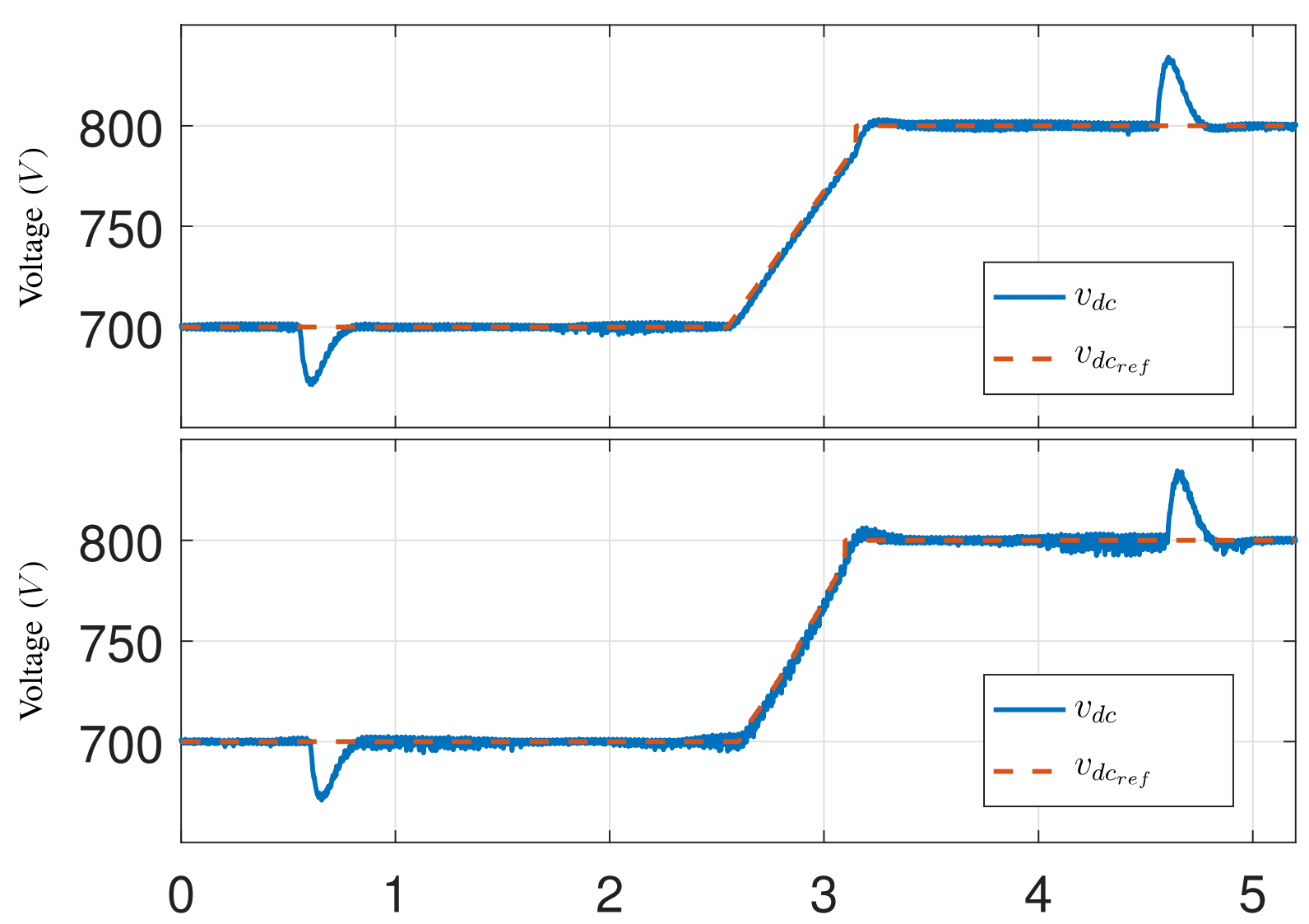

Time $(s)$

Fig. 8. Experiment: Behavior of the total dc-link capacitor voltage (solid) and its reference (dashed) for both the original algorithm (top) and the modified one (bottom).

enough it may be suppressed by the dead-time and delays presence. Therefore, this issue should be considered when selecting a proper value of $k_{1}, k_{2}, k_{3}$

Finally, the harmonic spectrum of the currents corresponding to Fig. 9 are shown in Fig. 12 where it can be seen a slight reduction in the switching frequency component when the modification is considered due to the reduction in the number of commutations. For clarity purposes, only the harmonics below the $20^{\text {th }}$ and between the $195^{\text {th }}$ and $205^{\text {th }}$ are shown. The THD value depicted refers to the one obtained by the power quality analyzer.

\section{CONCLUSIONS}

A specific controller for balancing the capacitor voltage in five-level diode-clamped rectifier has been designed and tested through simulation and experiments at the same time the remaining 


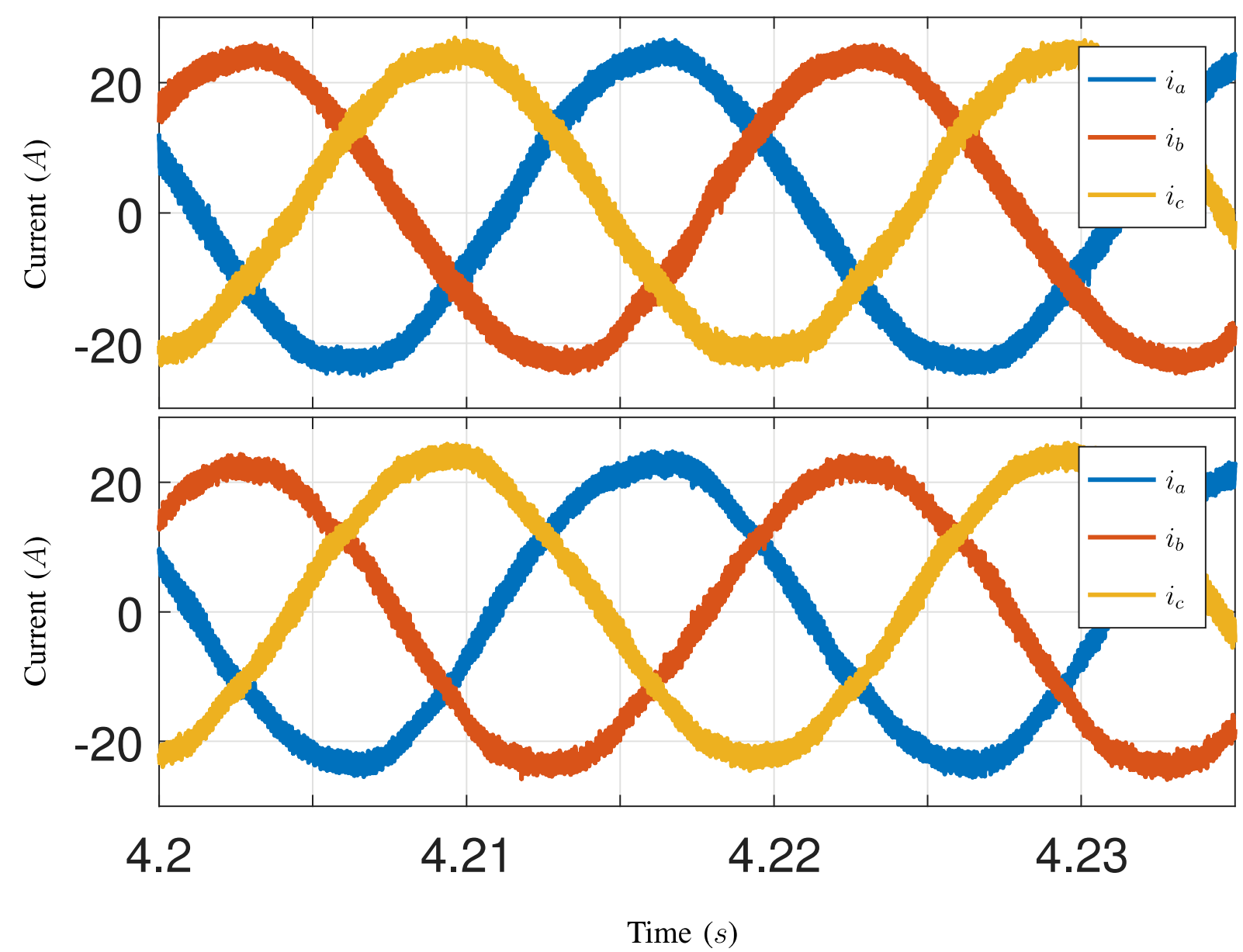

Fig. 9. Experiment: Behavior of the phase currents with the original algorithm (top) and the modified one (bottom). $R=60 \Omega$ and $v_{d c}=800 \mathrm{~V}$.

control objectives are assured. The way the rectifier has been presented allow the implementation of several strategies for current or power control, presenting in this paper a well-known DPC strategy. Simulation and experimental results have shown the good performance of the system under the proposed controllers, which are easier to implement than other existing approaches such as modifications of Virtual-Space-Vector. In addition, a modification in the algorithm allows the user to exploit the remaining degree of freedom associated with the homopolar component in such a way that the number of commutations is reduced.

This technique could be easily applied to DCC with more than five levels by applying the same procedure done here: defining a number of balancing signals equal to the number of levels minus 2; obtaining the dynamic of these signals in $\alpha \beta$ frame; defining some control inputs in terms 


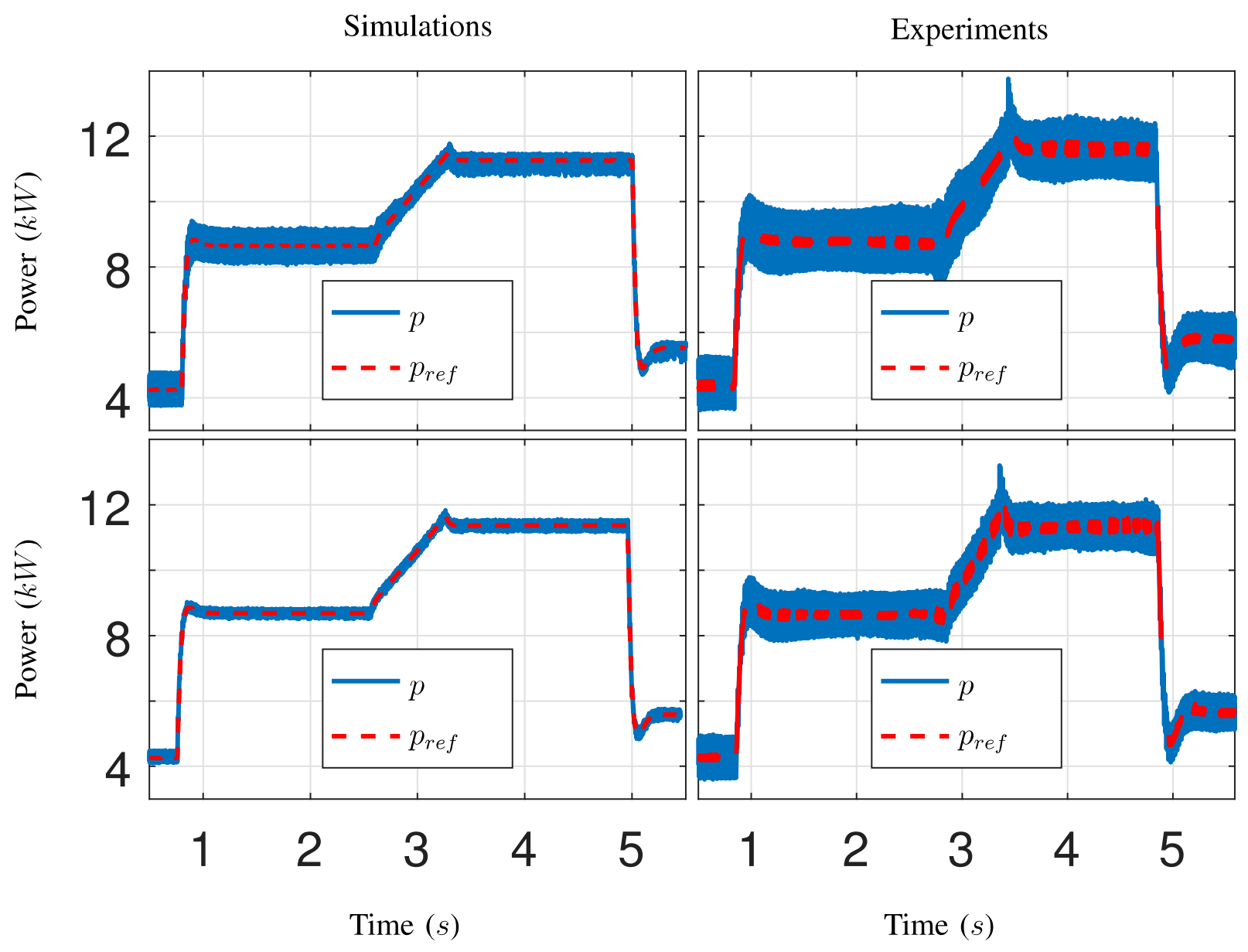

Fig. 10. Simulation and Experiment: Behaviour of the instant active power (solid) and its reference (dashed) for both the original algorithm (top) and the modified one (bottom).

of duty ratios to simplify these dynamics; and applying a simple control logic that guarantee stability in closed loop.

\section{REFERENCES}

[1] J. Rodriguez, L. G. Franquelo, S. Kouro, J. I. León, R. C. Portillo, M. M. Prats, and M. A. Pérez, "Multilevel converters: An enabling technology for high-power applications," Proceedings of the IEEE, vol. 97, no. 11, pp. 1786-1817, 2009.

[2] M. Malinowski, K. Gopakumar, J. Rodriguez, and M. A. Perez, "A survey on cascaded multilevel inverters," IEEE Transactions on Industrial Electronics, vol. 57, no. 7, pp. 2197-2206, July 2010.

[3] H. Abu-Rub, J. Holtz, J. Rodríguez, and Ge Baoming, "Medium-Voltage Multilevel Converters - State of the Art, Challenges, and Requirements in Industrial Applications," IEEE Transactions on Industrial Electronics, vol. 57, no. 8, pp. 2581-2596, 2010 . 

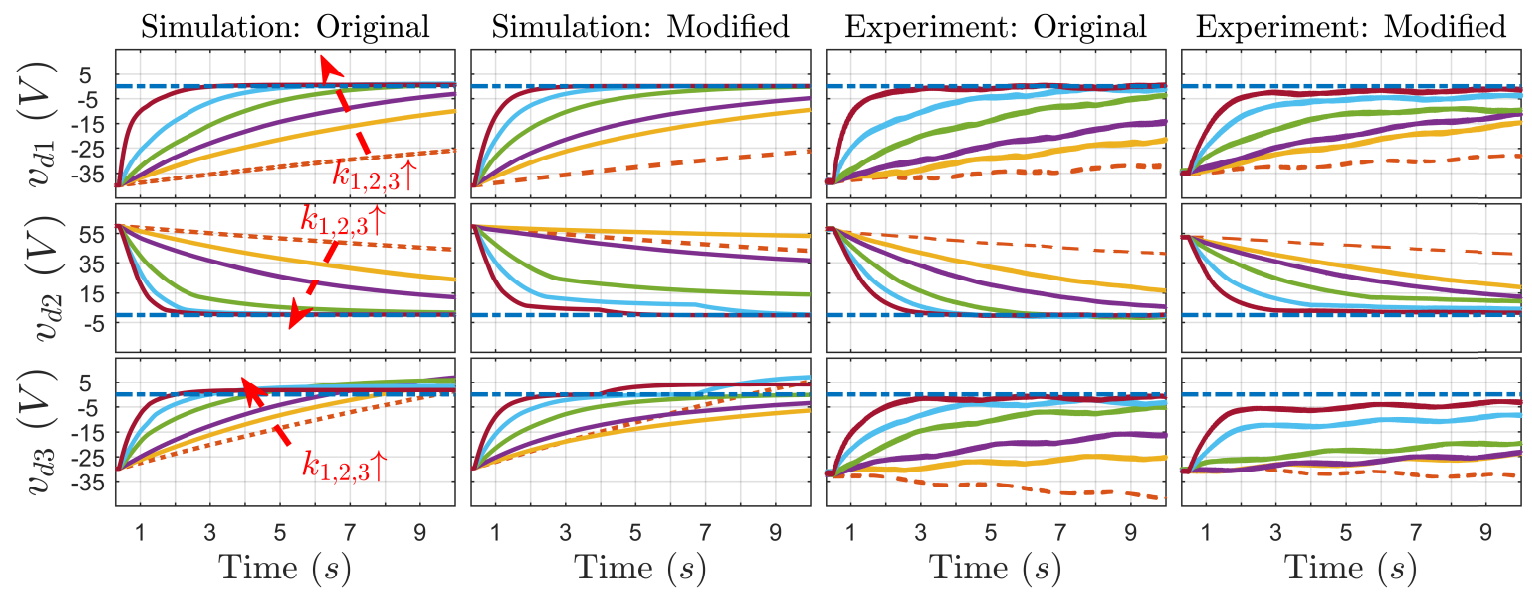

Fig. 11. Simulation and Experiment: Behavior of the error signals according to the value of $k_{1}, k_{2}, k_{3}$ for the original algorithm and the modified one either in simulations (two of the left hand side) and experiments (two of the right hand side). The values of $k_{1}, k_{2}, k_{3}$ are always equal and vary accordingly to $\left\{0,10^{-5}, 2 \cdot 10^{-5}, 5 \cdot 10^{-5}, 10^{-4}, 2 \cdot 10^{-4}\right\}$ along the different tests. The dashed curves are the ones with the balance control deactivated $\left(k_{1}=k_{2}=k_{3}=0\right)$ and the dashed-dotted ones are the zero-value curve.

[4] S. Kouro, M. Malinowski, K. Gopakumar, J. Pou, L. Franquelo, B. W. B. Wu, J. Rodríguez, M. Pérez, and J. Leon, "Recent Advances and Industrial Applications of Multilevel Converters," IEEE Transactions on Industrial Electronics, vol. 57, no. 8, pp. 2553-2580, 2010.

[5] A. Dekka, B. Wu, R. L. Fuentes, M. Perez, and N. R. Zargari, "Evolution of topologies, modeling, control schemes, and applications of modular multilevel converters," IEEE Journal of Emerging and Selected Topics in Power Electronics, vol. 5, no. 4, pp. 1631-1656, Dec 2017.

[6] J. I. Leon, S. Vazquez, and L. G. Franquelo, "Multilevel converters: Control and modulation techniques for their operation and industrial applications," Proceedings of the IEEE, vol. 105, no. 11, pp. 2066-2081, Nov 2017.

[7] Z. Zhao, J. Zhao, and C. Huang, "An improved capacitor voltage-balancing method for five-level diode-clamped converters with high modulation index and high power factor," IEEE Transactions on Power Electronics, vol. 31, no. 4, pp. 3189-3202, April 2016.

[8] F. Umbría, F. Gordillo, and F. Salas, "A controller for practical stability of capacitor voltages in a five-level diode-clamped power converter," Eur. J. Control, vol. 28, pp. 56-68, March 2016.

[9] F. Umbría, F. Gómez-Estern, F. Gordillo, and F. Salas, "Voltage balancing in five-level diode-clamped power converters," in Proc. 9th IFAC Symposium on Nonlinear Control Systems - NOLCOS'13, September 2013, pp. 365-370.

[10] Z. Shu, X. He, Z. Wang, D. Qiu, and Y. Jing, "Voltage balancing approaches for diode-clamped multilevel converters using auxiliary capacitor-based circuits," IEEE Transactions on Power Electronics, vol. 28, no. 5, pp. 2111-2124, 2013.

[11] C. Newton and M. Sumner, "Novel technique for maintaining balanced internal DC link voltages in diode clamped five-level inverters," IEE Proceedings -Electric Power Applications, vol. 146, no. 3, pp. 341-349, 1999.

[12] A. Rufer, "A five-level npc photovoltaic inverter with an actively balanced capacitive voltage divider," in Proceedings of PCIM Europe 2015; International Exhibition and Conference for Power Electronics, Intelligent Motion, Renewable Energy and Energy Management, May 2015, pp. 1-8. 


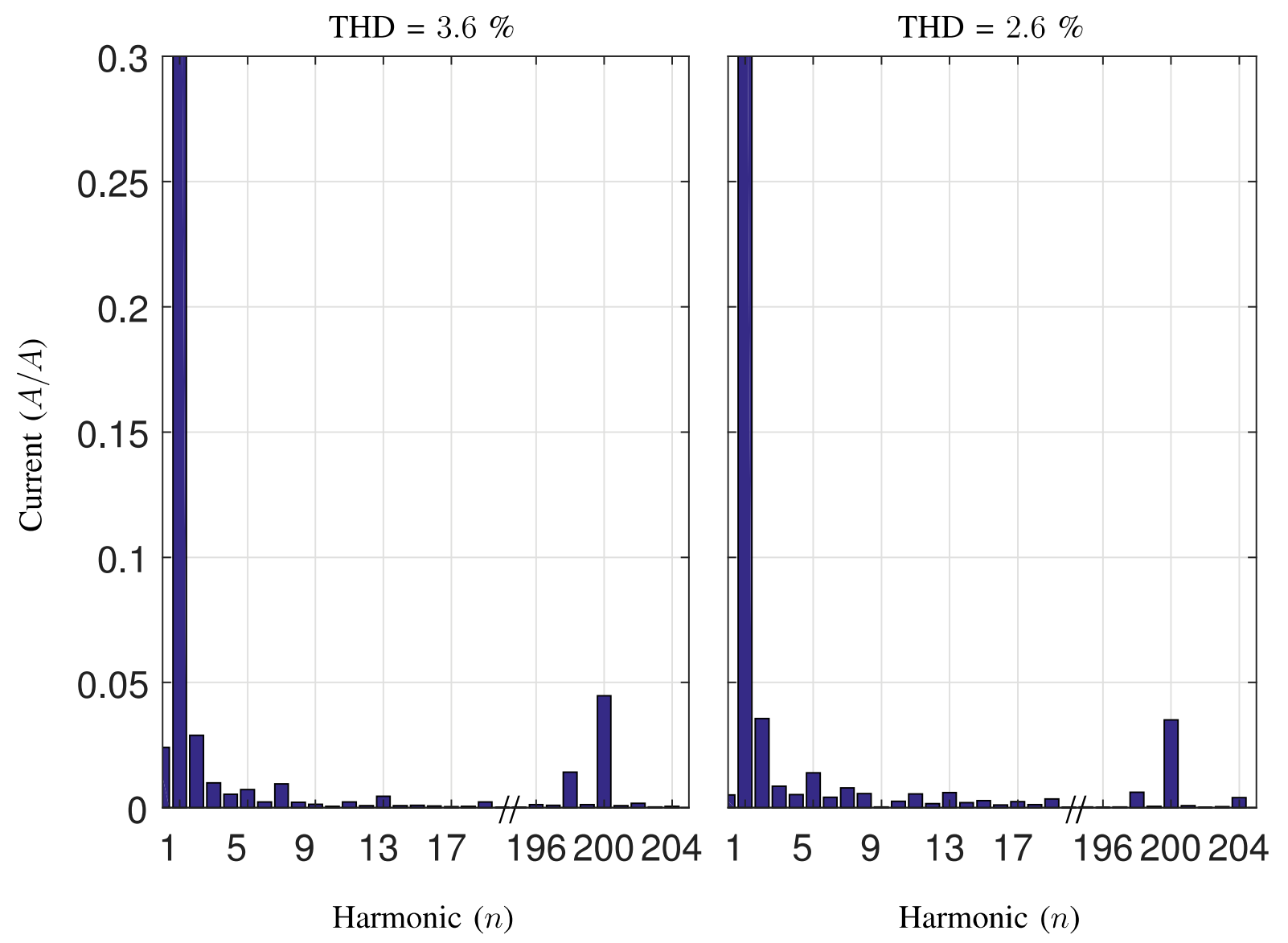

Fig. 12. Experiment: Harmonic Spectrum of the current in both the original algorithm (left) and the modified one (right). $R=60 \Omega$ and $v_{d c}=800 \mathrm{~V}$

[13] M. Saeedifard, R. Iravani, and J. Pou, "A space vector modulation strategy for a back-to-back five-level hvdc converter system," IEEE Transactions on Industrial Electronics, vol. 56, no. 2, pp. 452-466, Feb 2009.

[14] M. Marchesoni and L. Vaccaro, "Operating limits in multilevel mpc inverters with active front ends," in SPEEDAM 2010, June 2010, pp. 192-197.

[15] Z. Shu, N. Ding, J. Chen, H. Zhu, and X. He, "Multilevel SVPWM with dc-link capacitor voltage balancing control for diode-clamped multilevel converter based STATCOM," IEEE Transactions on Industrial Electronics, vol. 60, no. 5, pp. 1884-1896, 2013.

[16] M. Botao, L. Congwei, Z. Yang, and L. Fahai, "New SVPWM control scheme for three-phase diode clamping multilevel inverter with balanced DC voltages," IECON Proceedings (Industrial Electronics Conference), vol. 2, no. I, pp. 903-907, 2002.

[17] S. Busquets-Monge, S. Alepuz, J. Rocabert, and J. Bordonau, "Pulsewidth Modulations for the Comprehensive Capacitor Voltage Balance of n-Level Three-Leg Diode-Clamped Converters," IEEE Transactions on Power Electronics, vol. 24, no. 5, pp. 1364-1375, 2009.

[18] S. Busquets-Monge, S. Alepuz, J. Bordonau, and J. Peracaula, "Erratum to "Voltage Balancing Control of Diode-Clamped 
Multilevel Converters With Passive Front-Ends" [Jul 08 1751-1758]," IEEE Transactions on Power Electronics, vol. 24, no. 6, pp. 1666-1666, 2009. [Online]. Available: http://ieeexplore.ieee.org/lpdocs/epic03/wrapper.htm?arnumber=5071734

[19] P. Qashqai, A. Sheikholeslami, H. Vahedi, and K. Al-Haddad, "A new svm-based voltage balancing method for fivelevel npc inverter," in 2016 7th Power Electronics and Drive Systems Technologies Conference (PEDSTC), Feb 2016, pp. $511-516$.

[20] W. Yue, L. Ning, L. Su, C. Wulong, L. Wanjun, and W. Zhao'an, "Research on dc capacitor voltage self-balancing space vector modulation strategy of five-level npc converter," in 2014 IEEE Applied Power Electronics Conference and Exposition - APEC 2014, March 2014, pp. 2694-2699.

[21] D. Cui, Q. Ge, Z. Zhou, and B. Yang, "A closed-loop voltage balance method for five-level diode-clamped inverters," in IECON 2017 - 43rd Annual Conference of the IEEE Industrial Electronics Society, Oct 2017, pp. 503-508.

[22] J. Pou, R. Pindado, and D. Boroyevich, "Voltage-balance limits in four-level diode-clamped converters with passive front ends," IEEE Transactions on Industrial Electronics, vol. 52, no. 1, pp. 190-196, 2005.

[23] M. Marchesoni and P. Tenca, "Diode-clamped multilevel converters: a practicable way to balance dc-link voltages," IEEE Transactions on Industrial Electronics, vol. 49, no. 4, pp. 752-765, Aug 2002.

[24] J. Qin and M. Saeedifard, "Capacitor voltage balancing of a five-level Diode-Clamped Converter based on a predictive current control strategy," 2011 Twenty-Sixth Annual IEEE Applied Power Electronics Conference and Exposition (APEC), pp. 1656-1660, 2011.

[25] F. Gordillo, F. Gómez-Estern, and F. Salas, "An optimization approach for modulation in multilevel converters," in Proc. 42th Annual Conference of the IEEE Industrial Electronics Society - IECON'16, Oct. 2016, pp. 5033-5038.

[26] F. Umbría, F. Gordillo, and F. Salas, "Modeling and full decoupling control of a grid-connected five-level diode-clamped converter," Electric Power Components and Systems, vol. 45, no. 14, p. 1585-1598, 2017.

[27] A. Ventosa-Cutillas, P. Montero-Robina, F. Umbría, F. Cuesta, and F. Gordillo, "Integrated control and modulation for three-level NPC rectifiers," Sent to International Journal of Electrical Power \& Energy Systems, 2017.

[28] S. Vazquez, J. A. Sanchez, J. M. Carrasco, J. I. Leon, and E. Galvan, "A Model-Based Direct Power Control for Three-Phase Power Converters," Industrial Electronics, IEEE Transactions on, vol. 55, no. 4, pp. 1647-1657, 2008.

[29] H. Akagi, Y. Kanazawa, and A. Nabae, "Instantaneous Reactive Power Compensators Comprising Switching Devices without Energy Storage Components," IEEE Transactions on Industry Applications, vol. IA-20, no. 3, pp. 625-630, 1984.

[30] M. Malinowski, M. P. Kazmierkowski, and a. M. Trzynadlowski, "A comparative study of control techniques for PWM rectifiers in AC adjustable speed drives," Power Electronics, IEEE Transactions on, vol. 18, no. 6, pp. 1390-1396, 2003.

[31] G. Escobar, A. M. Stanković, J. M. Carrasco, E. Galván, and R. Ortega, "Analysis and design of direct power control (DPC) for a three phase synchronous rectifier via output regulation subspaces," IEEE Transactions on Power Electronics, vol. 18, no. 3, pp. 823-830, 2003.

[32] F. Umbría, F. Gordillo, and F. Salas, "Model-based NPC converter regulation for synchronous rectifier applications," in Proc. 40th Annual Conference of the IEEE Industrial Electronics Society - IECON'14, 2014, pp. 4669-4675. 


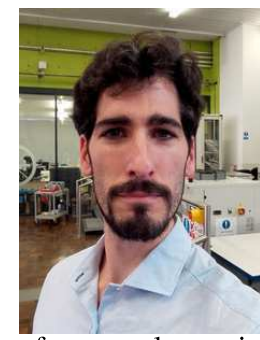

P. Montero-Robina was born in Seville, 1992. He received the degree in engineering of industrial technology and the M. degree in industrial engineering from the University of Seville, Seville, Spain in 2014 and 2016, respectively.

$\mathrm{He}$ is currently doing the Ph.D. with the Department of Systems Engineering and Automation at University of Seville, Seville, Spain. Previously, he collaborated as a researcher with the Electronic Engineering Department from the same University and several innovation companies related to the field of power electronic. He has also set-up and tested real grid-connected power converters.

His main research interests are control, design and development of power converters whether for grid-connected applications or particular ones such as electric vehicles, aircrafts,etc.

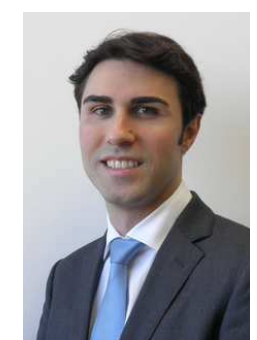

F. Umbría received his M.Sc. degree in Telecommunication Engineering and his M.Sc. and Ph.D. degrees in Automatics, Robotics, and Telematics from the University of Seville, Spain, in 2007, 2011, and 2013, respectively. He is a research and development engineer at ASM Assembly Systems in Munich, Germany. Before joining the company in 2015, he was working from 2008 to 2014 at the Department of Systems Engineering and Automation of the University of Seville. During 2012, he was a visiting research scholar at the Polytechnic Institute of New York University, USA.

His research interests include modeling, identification, and nonlinear control of electrical machines, drives, and power converters.

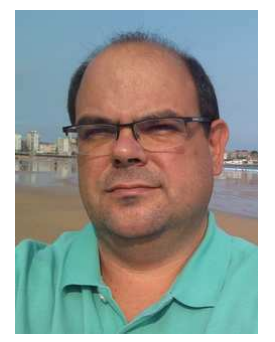

F. Salas was born in Almería, Spain, in 1970. He received his M.Eng. and Ph.D. degrees in electrical engineering from the University of Seville, Seville, Spain, in 1995 and 2002, respectively. From 1998 to 2006, he was an assistant professor with the Department of Systems Engineering and Automation, University of Seville. Since 2006, he has been an associate professor in the same department.

His current research interests include from the application of the bifurcation theory of dynamical systems to the stability analysis of nonlinear control systems and nonlinear control of power converters.

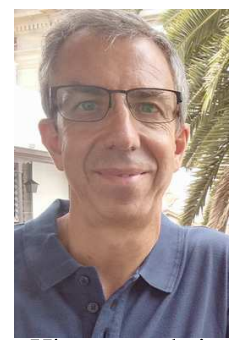

F. Gordillo received the Ingeniero Industrial and the Doctor Ingeniero Industrial degrees, from the Universidad de Sevilla, Spain in 1988 and 1994, respectively. Since 1989 he has been with the Department of Automatic Control of the Escuela Superior de Ingenieros in the Universidad de Sevilla where he is currently Full Professor. He is coauthor of Dinámica de Sistemas (Madrid: Alianza Editorial, 1997), coeditor of Stability Issues in Fuzzy Control (Berlin: Physica-Verlag, 2000) and author or co-author of more than 150 publications including book chapters, papers in journals and conference proceedings.

His research interests focus on nonlinear control with applications to mechanical, electromechanical and power electronics systems. 